exceptionally may have been three weeks. We observed that GGT values fell in 11 of 22 children with EHBA and rose in 12 of 22 with IHD. We expressed the degree of change in a fractional manner which we agree may be misleading. Nevertheless, while those with IHD may have fallen within the limits defined by Lau and Fung, 11 of 22 with EHBA would not have been considered for laparotomy. On the basis of our experience as reported in our paper, Drs Lau and Fung's assertion that repeated measurements of GGT could serve as a prelaparotomy, non-invasive screening test is an enticement to malpractice.

\section{Goodpasture's syndrome}

Sir,

I read with interest the paper by Dr Levin et al, ${ }^{1}$ and would like to bring to the authors' attention the fact that this syndrome in children was reported by $u^{2}{ }^{2}$ and $\mathrm{O}^{\prime}$ Connell $e t a l^{3}$ before Anand $e t a l^{4}$ and Siegler et al. ${ }^{5}$

Althought the authors correctly begin with the sentence 'Goodpasture's syndrome, a term describing the association of glomerulonephritis and lung haemorrhage', they give no evidence, including that of necropsy examination, that lung involvement occurred in their patients.

\section{SinAsi Ozsoylu Hacettepe University, Hacettepe, Ankara, Turkey}

\section{References}

${ }^{1}$ Levin M, Rigden SPA, Pincott JR, Lockwood CM. Barratt TM, Dillon MJ. Goodpasture's syndrome: treatment with plasmapheresis, immunosuppression, and anticoagulation. Arch Dis Child 1983;58:697-702.

2 Ozsoylu S, Hicsonmez G, Berkel I, Say B, Tinaztepe B. Goodpasture's syndrome (pulmonary hemosiderosis within nephritis). Clin Pediatr (Phila) 1976;15:358-60.

3 O'Connell EJ, Dower JC, Burke EC, Brown AL, Jr, McCaughey WTE. Pulmonary hemorrhage-glomerulonephritis syndrome. Relationship to Goodpasture's syndrome with report of a case in a 9 year old girl. Am J Dis Child 1964;108:302-8.

4 Anand SK, Landing BH, Heuser ET, Olson DL, Grushkin CM, Lieberman $\mathrm{E}$. Changes in glomerular basement membrane antigen(s) with age. $J$ Pediatr 1978;92:952-3.

$s$ Siegler RL, Bond RE, Morris AH. Treatment of Goodpasture's syndrome with plasma exchange and immunosuppression. Clin Pediatr (Phila) 1980;19:488-91.

\section{Dr Levin and co-workers comment:}

We thank Professor Ozsoylu for his letter, firstly drawing our attention to his earlier report of a child with Goodpasture's syndrome, and secondly questioning the use of the term Goodpasture's syndrome in our patients, in whom antiglomerular basement membrane antibody (anti GBM) induced nephritis was present without clinical evidence of lung haemorrhage.

We agree with Professor Ozsoylu's view that the term
Goodpasture's syndrome was originally used to described the clinical association of glomerulonephritis and lung haemorrhage. It therefore encompassed a heterogeneous group of patients with a variety of different pathological conditions, including Wegener's granulomatosis, polyarteritis, and glomerulonephritis with haemorrhagic pulmonary oedema.

The elucidation of the role of anti GBM antibodies in the pathogenesis of most patients with Goodpasture's syndrome has led to patients with the disorder being defined by immunological and pathophysiological rather than clinical criteria. It has led also to the recognition of patients who have anti GBM antibodies, but without simultaneous lung and kidney involvement. It remains a semantic problem as to whether the term Goodpasture's syndrome should only be used to describe patients with simultaneously clinically apparent kidney and lung disease, or whether its use should include all patients with anti GBM antibody disease, irrespective of the organ affected. We have followed the precedent set by others in using Goodpasture's syndrome as a widely accepted abbreviation for the disease which would be more accurately described as anti-basement membrane antibody induced glomerulonephritis and pneumonitis.

\section{Recurrent abdominal pain: a psychogenic disorder?}

Sir,

In drawing their conclusion that the syndrome of recurrent abdominal pain in childhood does not have a psychological basis, McGrath et al ${ }^{1}$ seem to be assuming that only children from emotionally unstable and chaotic backgrounds may suffer psychologically triggered somatic symptoms. In my experience, this is far from the case and the children referred to this paediatric outpatients clinic with recurrent abdominal pain fall into three broad categories:

(1) A small group who do come from highly disturbed backgrounds and who often have multiple symptoms suggestive of an emotional trigger. The diagnosis of the psychological causes is almost always made by the family practitioner, who is therefore very unlikely to refer the child to a gastroenterology unit for treatment. The prognosis for the pain is usually linked to the management of the whole family.

(2) Children with a strong family history of migraine who suffer episodes of abdominal pain, often with vomiting. They are often labelled as having the periodic syndrome or 'abdominal migrane' and it is possible that at least some may have food allergy. ${ }^{2}$

(3) The largest group resembles most those children described by McGrath $e t$ al. They are usually accompanied to 'outpatients' by one or both concerned parents, have no other symptoms, are completely normal on full examination, and their urine is normal on 'Dip-testing', microscopy, and culture. A consistent feature of their histories is that the episodes of abdominal pain induce a clear concern in the parents. Often, the first episode of pain has an 
obvious organic basis such as constipation or mesenteric adenitis, but one can see that this has been perpetuated by parental concern confirming and reinforcing the child's anxiety that there must be something seriously wrong. Successful management, as always, is dependent upon successful diagnosis. Thorough and confident reassurance and frank explanation are the cornerstones of treatment. Once the parents (and child) understand that abdominal pain may be perpetuated by anxiety and that a diagnosis of emotionally triggered pain does not mean that the family is labelled as uncaring or that the child is 'putting it on', the symptoms disappear. At follow up no such patient of mine has suffered further pain. I have no doubt that investigating them further in an attempt to provide a scientific, laboratory based diagnosis would not only draw a blank, as was the experience of McGrath et al, but would also enhance the view that something must be wrong if only it could be identified, and thus fuel the symptoms. The fact that all my patients in this group have been 'cured' by explanation supports my hypothesis better than any laboratory test could do.

\section{References}

1 McGrath PJ, Goodman JT, Firestone P, Shipman R, Peters S. Recurrent abdominal pain: a psychogenic disorder? Arch Dis Child 1983;58:888-90.

2 Egger J, Carter CM, Wilson J, Turner MW, Soothill JF. Is migraine food allergy? Lancet 1983;ii:865-8.

M Coulthard Department of Paediatric Nephrology, Guy's Hospital, St Thomas Street, London SE1 9RT

\section{Overheating in infancy}

Sir,

The article by Dr Bacon 'Overheating in infancy' ${ }^{1}$ brings back fond memories of 'sweating the fever out' at boarding school in Trinidad. Innumerable blankets were piled upon one by the housemaster, usually of European origin, in the fond hope of releasing the fever.

Trinidad is a Caribbean island, situated just 10 degrees above the Equator and with an average annual temperature of about $80^{\circ} \mathrm{F}$. Febrile convulsions account for $10 \%$ of all admissions to my paediatric unit at the Port of Spain Hospital. Yet it is difficult to teach mother and grandmother that wrapping up the baby and putting a wollen hat on its head will do more harm than good. Worms of course, are blamed for the fits. I am sure the experience is the same in all tropical countries.

1 Bacon CJ. Overheating in infancy. Arch Dis Child 1983;58: 673-4.

David BRATt

Port of Spain General Hospital, Charlotte Street,

Port of Spain, Trinidad, West Indies 